\title{
AGROBIODIVERSIDADE E OS SERVIÇOS AMBIENTAIS: PERSPECTIVAS PARA O MANEJO ECOLÓGICO DOS AGROECOSSISTEMAS NO ESTADO DO PARÁ
}

\author{
Diego de Macedo Rodrigues ${ }^{1}$; Maristela Marques da Silva ${ }^{2}$; Larissa Santos de Almeida ${ }^{3}$; João \\ Thiago Rodrigues de Souza ${ }^{4}$; Jorge Alberto Gazel Yared ${ }^{5}$; Antônio Cordeiro de Santana ${ }^{6}$. \\ ${ }^{1}$ Doutorando em Ciências Agrárias, Instituto de Ciências Agrárias (ICA), Universidade Federal Rural da Amazônia \\ (UFRA), Belém - PA, diegomacedoagronomo@ hotmail.com \\ ${ }^{2}$ Doutoranda em Ciências Agrárias, ICA, UFRA, Belém - PA, stela@ufpa.br \\ ${ }^{3}$ Doutoranda em Ciências Agrárias, ICA, UFRA, Belém - PA, larissaflorestal@yahoo.com.br \\ ${ }^{4}$ Doutorando em Ciências Agrárias, ICA, UFRA, Belém - PA, thiagronomo@ yahoo.com.br \\ ${ }^{5}$ Professor Doutor da UFRA, Belém - PA, jagyared@gmail.com \\ ${ }^{6}$ Professor Doutor da UFRA, Belém - PA, acsantana@superig.com.br
}

\begin{abstract}
RESUMO: A agrobiodiversidade, ou diversidade agrícola, constitui uma parte importante da biodiversidade e engloba todos os elementos que interagem na produção agrícola, sendo um componente essencial dos sistemas agrícolas sustentáveis. Desta forma, com este trabalho objetivou-se analisar as perspectivas de manejo sustentável dos solos e das pragas nos agroecossistemas paraenses, por meio da manutenção da agrobiodiversidade nas atividades produtivas. Utilizaram-se dados dos 143 municípios paraenses, oriundos do Censo Agropecuário de 2006, disponibilizados pelo Instituto Brasileiro de Geografia e Estatística (IBGE) e da Produção Anual dos Municípios (PAM), referente ao mesmo ano. Utilizou-se a análise fatorial, importante técnica de análise estatística multivariada, pela qual foram estimados escores fatoriais, dos quais foram estimados os índices utilizados na análise. Para o cálculo do IDA (Índice de Desempenho Agrícola) foram utilizadas 17 variáveis e no IDP (Índice de Desempenho Pecuário) foram utilizadas cinco ariáveis, todas referentes aos 143 municípios paraenses. Na busca por sistemas agrícolas sustentáveis no estado do Pará, de baixo uso de insumos e energeticamente eficientes, uma estratégia é restaurar a diversidade da paisagem agropecuária dentro e no entorno do estabelecimento agrícola, nos quais a diversidade pode ser melhorada no tempo, o que pode ser alcançado por meio da rotação de culturas por exemplo, e, no espaço, pode-se otimizar a forma de cultivos de cobertura, adotar policulturas, sistemas agrossilvipastoris, cercas vivas, conservação de fragmentos de florestas, corredores ecológicos e matas ciliares, dentre outros.
\end{abstract}

PALAVRAS-CHAVE: agricultura familiar, agropecuária, sustentabilidade.

\section{AGROBIODIVERSITY AND ENVIRONMENTAL SERVICES: PROSPECTS FOR ECOLOGICAL MANAGEMENT AGROECOSYSTEMS OF THE STATE OF PARÁ}

ABSTRACT: Agrobiodiversity, or agricultural diversity, is an important part of biodiversity and encompasses all elements that interact in agricultural production and is an essential component of sustainable agricultural systems. Thus, this work aimed to analyze the prospects for sustainable management of soil and pests in agroecosystems Pará, through the maintenance of agrobiodiversity in productive activities. We used data from 143 municipalities in Pará, from the 2006 Agricultural Census, provided by the Brazilian Institute of Geography and Statistics (IBGE) and the Municipalities Annual Production (MAP) for the same year. We used factor analysis, an important technique of multivariate statistical analysis, which were estimated by factor scores, which were estimated indexes used in the analysis. To calculate the IDA Performance Index (Agricultural) and 17 variables were used in the IDP Performance Index (Livestock) were used five variables, referring to all 143 municipalities in Pará. In the search for sustainable agricultural systems in the state of Pará, low-input and energy-efficient strategy is to restore the diversity of the agricultural landscape in and around the agricultural establishment, in which diversity can be improved over 
time, which can be achieved through crop rotation for example, and in space, one can optimize the form of cover crops, adopt polycultures, agroforestry systems, hedgerows, conservation of forest fragments, riparian corridors and, among other .

KEY-WORDS: agriculture, farming family, sustainability.

\section{INTRODUÇÃO}

Os serviços ambientais são condições e processos através dos quais os ecossistemas naturais e as espécies que o compõem, mantém e suprem a vida humana (DAILY, 1997). Este conceito engloba o fornecimento, oferta, produção, proteção ou manutenção de um conjunto de bens e serviços que as pessoas consideram ser importantes (CHEE, 2004).

Para Boyd e Banzhaf (2007) os serviços ambientais não são os benefícios que os humanos obtêm dos ecossistemas, mas sim, os componentes ecológicos diretamente consumidos ou usufruídos que propocionam bem-estar humano. Sob essas bases, Fisher et al. (2009), propõem que os serviços ambientais são os aspectos dos ecossistemas utilizados (ativa ou passivamente) para produzir bem-estar humano. Ainda reforçam que é preciso ter uma definição consistente e de importante base ecológica, pois os serviços dos ecossistemas são uma função de interações complexas entre as espécies e seu ambiente abiótico, uso e utilização de padrões complexos e percepções diferentes por parte dos beneficiários.

A agrobiodiversidade, ou diversidade agrícola, constitui uma parte importante da biodiversidade e engloba todos os elementos que interagem na produção agrícola, como os cultivos, criações, plantas espontâneas, parasitas, pragas, polinizadores, remanescentes de floresta, inimigos naturais e os simbiontes. Dessa forma, a agrobiodiversidade é um componente essencial dos sistemas agrícolas sustentáveis e um de seus princípios é justamente a diversificação de cultivos. Essa diversificação promove os serviços ambientais dos agroecossistemas, principalmente no que tange a ciclagem de nutrientes e controle biológico de pragas. Um maior número de espécies em determinado ecossistema, associado a outros fatores ecológicos, assegura maior estabilidade e menor necessidade de insumos externos, como fertilizantes e agrotóxicos (SANTILLI, 2009).

Diversas especificidades da agricultura familiar têm sido apontadas como potencialmente amigáveis ao meio ambiente, especialmente no que diz respeito ao uso de recursos naturais e preservação de mananciais. A diversidade de atividades em uma unidade produtiva, por exemplo, é vista como um elemento que favorece a geração de serviços ambientais. Quanto maior é a diversidade de espécies, maiores oportunidades os sistemas naturais terão para 
se recuperar das agressões sofridas (ALTAIN, 2008).

A simplificação da biodiversidade para fins agrícolas gera um ecossistema artificial, que requer constante intervenção humana para que o sistema continue a ser produtivo, pois sem esta intervenção a sustentabilidade do sistema fica comprometida (ALTIERI et al., 2003). Se por um lado a simplificação do ambiente agrícola favorece a condução e manutenção das áreas cultivadas, por outro o desequilíbrio causado por essa substituição dos serviços ambientais dos artrópodes, por exemplo, acaba favorecendo o surgimento de pragas, pelo fato dessas encontrarem nestes ambientes condições ideais para o seu desenvolvimento, dentre estes, a baixa ocorrência de inimigos naturais. Em contraponto, a diversificação de um agroecossistema pode ser realizada de várias formas, que vão desde o consórcio de culturas, passando pela rotação, até os sistemas agroflorestais. Esses sistemas favorecem os serviços ambientais dos artrópodes promovendo o aumento da matéria orgânica nos solos e conservam a diversidade de inimigos naturais.

Em nenhum outro aspecto da agricultura as consequências da redução da biodiversidade são tão evidentes quanto na esfera do manejo de pragas. A exemplo disto, muitos cultivos são conduzidos sob o uso intensivo de pesticidas, o que podem agredir o meio ambiente e a saúde dos agricultores, provocando redução populacional de inimigos naturais e o desenvolvimento de linhagens de ácaros resistentes (ALTIERI, 1994; BELLOTTI et al., 1999; HAJEK, 2004).

Por outro lado, a biodiversidade do solo é um importante indicador da sustentabilidade de ecossistemas agrícolas e o incremento da produção agrícola não pode ser feito em detrimento da aptidão das terras e das complexas relações existentes entre características de solo e diversidade biológica. A definição da sustentabilidade de sistemas de produção exige que se considere o papel da fauna no comportamento dos solos como promotores de serviços ambientais. Desta forma, os estudos de fluxos de nutrientes e de água para as plantas devem necessariamente incluir a biodiversidade edáfica, no contrário, essa visão reducionista das complexas interações existentes no ambiente pode conduzir a degradação gradativa das terras pela agricultura.

Segundo KARLEN et al. (1997), a qualidade do solo tem sido conceituada como a capacidade que um determinado tipo de solo apresenta, em ecossistemas naturais ou em agroecossistemas, para desempenhar uma ou mais funções relacionadas à sustentação da atividade, da produtividade e da diversidade biológica, à manutenção da qualidade do ambiente, à promoção da saúde das plantas e dos animais.

O Estado do Pará possui vantagens comparativas naturais e históricas para o desenvolvimento de atividades agropecuárias. As características edafoclimáticas locais, o 
preço do terra ser considerado baixo em relação aos preços praticados nos demais estados das outras regiões do país e a riqueza de recursos florestais e não florestais da floresta amazônica possibilitam o bom desenvolvimento de diversas atividades produtivas, dentre os quais são destacadas as lavouras de arroz, soja, feijão caupi, mandioca, milho, abacaxi, banana, coco-dabaía, dendê, a pecuária bovina e bubalina, além do extrativismo madeireiro e de produtos como a castanha-do-pará e o açaí. Adicionalmente, o fato do estado estar em posição geográfica privilegiada, confere vantagens locacionais relacionadas aos mercados nacional e internacional, apresentando grandes perspectivas produtivas (SANTANA, 1988).

O potencial produtivo do Pará também faz surgir a preocupação no tocante ao manejo sustentável dos recursos naturais explorados nas atividades agropecuárias, considerando que aspectos como a sustentabilidade ambiental e manutenção da floresta se tornaram fundamentais nas atividades produtivas. Desse modo, o uso da biodiversidade leva a uma nova perspectiva para o manejo de pragas e do solo, em uma perspectiva ecológica, holística, integradora e sustentável, cenário em que surge um desafio para a agricultura paraense: identificar as melhores práticas de manejo dos agroecossistemas que estimulem a biodiversidade e favoreça os processos ecológicos vitais para a sustentabilidade desses sistemas agrícolas, por meio da promoção dos serviços ecológicos dos artrópodes, tais como controle biológico e ciclagem de nutrientes.

Objetivou-se analisar as perspectivas de manejo sustentável dos solos e das pragas nos agroecossistemas paraenses, por meio da manutenção da agrobiodiversidade nas atividades produtivas.

\section{MATERIAL E MÉTODOS}

Utilizaram-se dados dos 143 municípios paraenses, oriundos do Censo Agropecuário de 2006, disponibilizados pelo Instituto Brasileiro de Geografia e Estatística (IBGE) e da Produção Anual dos Municípios (PAM), referente ao mesmo ano. Utilizou-se a análise fatorial, importante técnica de análise estatística multivariada, pela qual foram estimados escores fatoriais. A análise fatorial é utilizada para analisar a estrutura das interrelações entre um grande número de variáveis, como um método matemático qualitativo que reorganiza a informação de um conjunto de dados de amostragem. A análise descobre novas variáveis, chamadas de fatores, essas dimensões latentes comuns facilitam a compreensão da estrutura da nuvem de dados através da reunião da maioria da variabilidade dos dados (DAVIES; FEARN, 2004; SANTANA, 1988).

Os escores calculados para cada um dos municípios foram padronizados, normalizados e, somente então, puderam ser utilizados para se estimar dois índices de desempenho 
(agrícola, pecuário) referentes a cada município paraense. Hair et al. (2005) explica que os escores fatoriais são medidas compostas criadas para a observação de cada fator extraído na análise fatorial, sendo que os pesos fatoriais são utilizados em conjunto com os valores da variável original para calcular o escore de cada observação, neste caso cada um dos municípios paraenses.

Para tornar os valores dos escores fatoriais positivos e entre zero e um para permitir a hierarquização dos municípios, foi utilizada a seguinte fórmula de normalização.

1) $F_{j \text { Normalizado }}=\left(F_{j}-F_{j \min }\right) /\left(F_{j \max }-F_{j \min }\right)$

2) $\mathrm{ID}_{\mathrm{i}}=\Sigma \frac{\lambda \mathrm{j}}{\Sigma \lambda} \cdot \mathrm{F}_{\mathrm{j}}$

Em que:

ID = índice de desempenho do i-ésima município;

$\lambda \mathrm{j}=\mathrm{j}$-ésima raiz característica, o valor de fatores extraídos na anális;

$\mathrm{F}_{\mathrm{ji}}=\mathrm{j}$-ésimo escore fatorial do i-ésimo município;

$\Sigma \lambda=$ somatória das raízes características referentes aos fatores extraídos, ou seja, participação relativa do fator na explicação da variância total captada pelos fatores extraídos (HAIR et al., 2004).

As análises estatísticas foram realizadas

A classificação dos municípios pelos índices obtidos foi discutida no contexto das perspectivas de manejo ecológico do solo e de pragas para as atividades agropecuárias dos principais municípios, em função das peculiaridades de cada um e, dentro do contexto de uso racional da bioagrodiversidade para promover uma agricultura sustentável. Foram estimados dois índices: Índice de Desempenho Agrícola (IDA) e Índice de Desempenho Pecuário (IDP). Estes índices foram estimados a partir de escores fatoriais associados a cada um dos 143 municípios do estado do Pará, calculado de grupos diferentes de variáveis em função das características de cada índice.

Para estimação dos índices de desempenho (ID) substitui-se estes pesos e escores na seguinte equação:

utilizando-se o software SPSS versão 7.5. As Figuras (mapas esquemáticos) foram confeccionadas com o software ArcGis versão 10.0 .

\section{ANÁLISE DE DADOS E VARIÁVEIS} Índice de Desempenho Agrícola (IDA)

Para o cálculo do IDA foram utilizadas 17 variáveis referentes aos 143 municípios paraenses, destacando-se que todos os valores foram relativizados, isto é, foi calculada a porcentagem da participação do município em relação ao total no estado: Área plantada com arroz; Área plantada com feijão; Área plantada com milho; Área plantada com soja; Área plantada com cacau; Área plantada com café; Área plantada pimenta-do-reino; Área plantada com guaraná; Área plantada com coco-da-baía; Área plantada com dendê; Área 
plantada com banana; Área plantada com abacaxi; Área plantada com laranja; Área plantada com maracujá; Área plantada com melancia; Área plantada com seringueiras; Área plantada com mandioca. Tratam-se das culturas mais cultivadas e/ou economicamente significativas da agricultura no estado, segundo os dados da PAM do ano de 2006, disponibilizada pelo IBGE. O modelo extraiu seis fatores com autovalores maiores que 1 , que por sua vez explicaram $62,66 \%$ da variação dos dados.

\section{Índice de Desempenho Pecuário - IDP}

Para o cálculo de IDP foram utilizadas cinco variáveis referentes aos 143 municípios paraenses: Número de cabeças de bovinos por hectare; Número de cabeças de bubalinos por hectare; Número de cabeças de caprinos por hectare; Número de cabeças de ovinos por hectare; Número de cabeças de suínos por hectares; Número de cabeças de aves por hectare. Tratam-se das criações mais comuns nos estabelecimentos agrícolas paraenses segundo os dados do IBGE. O modelo elegeu dois fatores com autovalores superiores a um, sendo que estes explicaram $61,81 \%$ da variação dos dados.

\section{RESULTADOS E DISCUSSÃO}

A análise originou o ranking dos 20 municípios que apresentaram os maiores valores de IDA, isto é, relacionou aqueles que obtiveram o melhor desempenho agrícola do estado, considerando uma análise integrada das variáveis produtivas (Tabela 1).

Tabela 1. Índice de Desempenho Agrícola dos 20 municípios melhores colocados entre os 143 municípios do estado do Pará.

\begin{tabular}{llllll}
\hline Posição & IDA & Município & Posição & IDA & Município \\
\hline $1^{\circ}$ & 0,38313 & Santarém & $11^{\circ}$ & 0,24579 & Igarapé-Açu \\
$2^{\circ}$ & 0,34199 & Tomé-Açu & $12^{\circ}$ & 0,23761 & Belterra \\
$3^{\circ}$ & 0,32786 & Medicilândia & $13^{\circ}$ & 0,23606 & Uruará \\
$4^{\circ}$ & 0,31278 & Monte Alegre & $14^{\circ}$ & 0,23457 & Ipixuna do Pará \\
$5^{\circ}$ & 0,30798 & Acará & $15^{\circ}$ & 0,23340 & Novo Repartimento \\
$6^{\circ}$ & 0,30269 & Moju & $16^{\circ}$ & 0,23211 & Santa Maria das Barreiras \\
$7^{\circ}$ & 0,27814 & Capitão Poço & $17^{\circ}$ & 0,23049 & Curuçá \\
$8^{\circ}$ & 0,27303 & Paragominas & $18^{\circ}$ & 0,22801 & Itupiranga \\
$9^{\circ}$ & 0,25954 & Altamira & $19^{\circ}$ & 0,22762 & São Miguel do Guamá \\
$10^{\circ}$ & 0,25441 & Rurópolis & $20^{\circ}$ & 0,22400 & Baião \\
\hline
\end{tabular}

O município de Santarém, localizado na mesorregião oeste paraense foi $\mathrm{o}$ melhor classificado, o que se pode atribuir à maior participação do município na produção de soja e arroz no estado. Nos últimos anos a produção de soja no Pará saltou de 1.353 
toneladas em 1997 para 99.437 toneladas em 2004. Santarém se tornou um dos municípios da nova fronteira de ocupação agrícola, situação favorecida principalmente pela perspectiva de asfaltamento da rodovia BR 163. Neste mesmo cenário, a possibilidade de implantação de um porto graneleiro no município gerou, por exemplo, especulação fundiária, aumentou o fluxo de produtores que imigraram de outras regiões do país, onde a terra é mais valorizada, possibilitando a compra de áreas maiores que aquelas que possuíam, diante, diga-se de passagem, do preço relativamente baixo das terras paraenses. Sob o aspecto produtivo, muitos dos produtores já instalados na região, que produziam arroz, por exemplo, migraram para o cultivo da soja. A imigração dos agricultores de outras regiões do país acarretou problemas, como perdas severas na qualidade do solo decorrentes do manejo inadequado de áreas que receberam tecnologia e insumos utilizados nas regiões de origem destes produtores.

$\mathrm{Na}$ caracterização do desempenho agrícola dos municípios em função dos intervalos de valores, em que os aqueles cobertos pela cor mais clara representam o intervalo com menor IDA $(0,10-0,17)$, é possível perceber a baixa aptidão agrícola da mesorregião do Marajó, quando se considera a análise integrada das variáveis produtivas. Por outro lado, pode-se evidenciar a grande exploração agrícola na mesorregião Nordeste
Paraense e na microrregião do Baixo Amazonas.

Depois de Santarém, os maiores desempenhos agrícolas municipais são de Paragominas, Santana do Araguaia, Belterra, Ulianópolis e Dom Eliseu. Os municípios de Santarém, Santana do Araguaia e Belterra respondem respectivamente por $62 \%$ da produção de soja no estado (IBGE 2004).

Landis et al. (2000) alerta que em monoculturas as pragas exibem taxas de colonização mais altas, tempos de permanência mais longos, menos barreiras ao encontro do hospedeiro e maior potencial reprodutivo, certamente por aumentar a facilidade com que as mesmas podem localizar seu alimento. Ademais, a disponibilidade de grande quantidade de alimento diminui a competição intraespecífica e a taxa relativa de mortalidade (ATKINS, 1978). Contrariamente, nestes sistemas simplificados de produção de grãos, os inimigos naturais não encontram as condições ideais para sobreviver e se multiplicar, agravando mais ainda as perdas com pragas, incentivando cada vez mais o uso de defensivos químicos (NICHOLLS et al., 1999).

A redução na biodiversidade de plantas e os efeitos resultantes afetam as funções dos ecossistemas, com conseqüências sobre a produtividade agrícola e a sustentabilidade dos agroecossistemas, uma vez que as características intrínsecas da auto-regulação dos ecossistemas naturais proporcionadas pela 
biodiversidade são perdidas em função das perturbações inerentes ao processo de forma extrema nas monoculturas. Portanto, uma estratégia-chave na agricultura sustentável é reincorporar a diversidade na paisagem agrícola e manejá-la de forma mais efetiva (GLIESSMAN, 2001; ALTIERI et al., 2003).

Nenhum outro aspecto dos sistemas agrícolas proporciona tantos serviços ecológicos fundamentais para assegurar a proteção de plantas contra as pragas quanto à diversidade da vegetação (ALTIERI; LETOURNEAU, 1982; ANDOW, 1991). Desta forma, incentiva-se a diversificação no tempo e no espaço para os cultivos de grãos na microrregião do Baixo Amazonas. Uma estratégia importante para se melhorar o habitat para os inimigos naturais no agroecossistema é o manejo da vegetação do entorno, principalmente através da valorização das bordas, áreas companheiras e manutenção de corredores ecológicos, que podem fornecer alimento e abrigo para inimigos naturais, funcionando como “insetários selvagens". A manutenção de áreas de ervas espontâneas dentro e no entorno da lavoura, dentro de certos limites, podem favorecer as populações de inimigos naturais (LANDIS et al., 2000). Algumas plantas provêem alimento alternativo a estes predadores na forma de pólen e néctar, que podem mantê-los na ausência de presa, além de proverem também abrigo (MORAES et al., 1993; DEMITE; FERES, 2005).
A diversificação dos cultivos no Baixo Amazonas pode também ter efeitos no solo. Mendonça et al. (2001) afirma que a combinação de espécies arbóreas com culturas agrícolas e/ou animais proporcionaria a melhoria nas propriedades físico-químicas de solos degradados, bem como na atividade de microrganismos, considerando a possibilidade de um grande número de fontes de matéria orgânica, reduzindo o uso de fertilizantes.

Tomé-açu que apresentou o segundo maior índice, não lidera nenhum ranking de produção entre as principais culturas no estado, contudo encontra-se entre os 10 maiores cultivadores de diversas culturas como: seringueira, coco-da-baía, cacau, dendê, maracujá, laranja, pimenta-do-reino e mandioca. O município demonstrou sua maior propensão à policultivos. Em sistemas agrícolas consorciados, minimizar a competição e maximizar a complementação interespecífica é uma estratégia fundamental (FRANCIS et al., 1976; VANDERMEER, 1989). Os mecanismos envolvidos no controle de pragas através da diversificação por policultivos são em geral decorrentes do aumento da abundância e/ou diversidade de inimigos naturais pela maior disponibilidade de alternativas de alimento e abrigo, dificuldades de colonização e reprodução das pragas, repelência química, mascaramento e/ou inibição de alimentação por plantas nãohospedeiras, prevenção de movimento e/ou imigração e otimização da sincronia entre 
ciclos de pragas e seus respectivos inimigos naturais.

Estes aspectos favorecem a sustentabilidade das produções neste município através do favorecimento do controle biológico conservativo. Segundo Schoohonven et al. (1998), herbívoros que chegam a um agroecossistema usam, para localizar seu hospedeiro (planta), estímulos visuais ou químicos. Em situação de policultivos, há uma ampla variedade de estímulos, que podem misturar-se uns aos outros, atuando no confundimento dos herbívoros que estão imigrando para esse sistema. Desta forma, estes cultivos apresentam menores danos por herbívoros e, por esta razão, menor probabilidade de uso de defensivos químicos, resultando em produtos mais saudáveis aos consumidores.

Medicilândia é o maior produtor de café, banana e cacau, além de ser um dos cinco municípios que mais cultivam guaraná. Para este município esta posição de destaque em culturas diversificadas é oriunda de um processo histórico que se intensificou a partir da instalação da Comissão Executiva do Plano da Lavoura Cacaueira (CEPLAC) na região e do Programa de Diretrizes para Consolidação da Cacauicultura Nacional (PROCACAU) em 1978 (CALVI, 2008).

Em estudo realizado no ano de 2007 no território da Transamazônica, Brandão (2008) identificou área de aproximadamente 45.780 ha de cacau em sistemas agroflorestais (SAFs), cultivados por 4.482 famílias, sendo
73,7\% destes considerados em efetiva produção e 26,3\% constituíam SAFs em desenvolvimento. Só no município de Medicilândia são encontrados 38,62\% desses SAFs, o que corrobora com a classificação deste município no IDA, visto que as bases para os SAFs na região da Transamazônica são banana, café e cacau.

Esses sistemas, embora não restaurem aspectos importantes das comunidades florestais, como estrutura e biodiversidade, se bem planejados, podem aproximar-se ecologicamente dessas comunidades, recuperando funções essenciais para a sustentabilidade, como a ciclagem de nutrientes, além de fornecerem renda ou produção de subsistência ao produtor rural (MACDICKEN; VERGARA, 1990). Este aspecto indica que o município de Medicilândia está em um bom caminho de sustentabilidade agrícola.

Arato et al. (2003) em trabalho realizado em Viçosa-MG concluíram que os valores obtidos de produção de liteira (serapilheira) total e frações - foram semelhantes aos encontrados em florestas estacionais semideciduais da região Sudeste do Brasil, o que permite inferir que o sistema se comportou de maneira análoga a uma floresta nativa em termos de dinâmica da liteira. A elevada taxa de decomposição da liteira indica a rápida liberação e $\mathrm{o}$ conseqüente reaproveitamento dos nutrientes por parte do sistema radicular da vegetação do SAF. Os SAFs, portanto, podem favorecer o 
reaproveitamento dos nutrientes e a manutenção da fauna edáfica, favorecendo a produtividade dos cultivos a custos inferiores.

Nos últimos anos algumas áreas com cultivos de cacau em Medicilândia foram certificadas como cultivos orgânicos. Em trabalho com organismos do solo em sistemas de cultivo orgânico e convencionais, Bettiol et al. (2002), observaram que, de modo geral, o número de indivíduos de microartrópodes foi superior no sistema orgânico, comparado ao sistema convencional, refletindo no maior índice de diversidade de espécies (Shannon). Pode-se, relacionar que os cultivos da Transamazônica se associam a uma condição de sustentabilidade em relação a manutenção da biodiversidade do solo e ainda, quanto à qualidade dos produtos isentos de resíduos químicos.

A maior produção de feijão e milho no município de Monte Alegre o colocou na quarta posição. Em quinto lugar, Acará é o maior produtor de mandioca e segundo maior de coco-da-baía. A produção das culturas de feijão, milho e mandioca, salvo alguns cultivos, no Estado do Pará é feita por agricultores familiares. Reconhecidamente é no Pará que existe o maior número de assentamentos rurais do país que tradicionalmente exploram cultivos das lavouras temporárias para sua subsistência.

A agricultura de terra firme amazônica predominantemente se caracteriza pela prática de corte e queima, na qual pequenas áreas são desmatadas, florestas ou capoeiras (vegetação secundária), queimadas e em seguida plantadas. Derrubadas e queimadas que vêm ocorrendo no estado do Pará expõem o solo diretamente ao processo de erosão e degradação, além de promover o desaparecimento dos organismos da fauna edáfica.

Em experimentos no estado do Pará, Leitão-Lima e Teixeira (2002) concluíram que as densidades de invertebrados terrestres apresentaram níveis elevados e os grupos de Acari e Collembola são dominantes, independente do tipo de vegetação. Acacia mangium Willd. (acácia), Inga edulis Mart. (ingá) e Sclerolobium paniculatum Vogel (taxi-branco) e em uma capoeira com seis anos de pousio sem enriquecimento em relação à áreas sem pousio. O pousio da área para a recuperação da capoeira regenera a fauna edáfica, trazendo benefícios aos solos, no entanto, a prática tradicional do fogo, elimina toda a cobertura do solo e, por conseguinte, a fonte de alimento, limitando o número de nichos ecológicos e acarretando ainda em uma simplificação da cadeia alimentar. Nesse aspecto, intensificam-se os efeitos sobre a fauna do solo, que foi privada de sua alimentação e abrigos, refletindo sobre a sua densidade e diversidade, e consequentemente, sobre a fertilidade do solo (PINHEIRO, 2007).

Estudando a influência do método de preparo da área sobre a mesofauna do solo, Ferreira e Kato (2003) observaram baixa densidade de Collembola na área queimada 
sugerindo sensibilidade deste grupo de insetos às áreas degradadas. Avaliando a fauna do solo em áreas com Eucaliptus ssp. o estudo mostrou que o número de indivíduos de Acari nesta mesma condição foi superior, tanto no período seco como no período chuvoso. Portanto, é necessária a busca de alternativas que sejam menos impactantes ao solo, como a roça-sem-queima, que possibilita o plantio sem o uso do fogo trazendo benefícios importantes ao solo como o incremento da fauna edáfica, contribuindo para a fertilidade do solo, e consequentemente para a produtividade das culturas do milho, feijão e mandioca.

A sexta colocação do município de Moju na classificação do IDA, tem grande explicação no fato deste ser o maior produtor de coco-da-baía e segundo maior de dendê do estado. Neste município há a presença de um dos maiores plantios individuais de coco do país. Trata-se da Fazenda Socôco, fundada no ano de 1979, quando a empresa visava à integração vertical de sua produção, buscando garantir a qualidade do produto e um grande volume de produção (REBELO et al., 2001). Grandes cultivos e monoculturas como estes, contudo, somente conseguem alta produtividade com grandes custos ambientais e uso de defensivos agrícolas.

Uma alternativa para o manejo ecológico de pragas, neste caso, seria o manejo da vegetação espontânea, que influencia a diversidade e a abundância de insetos herbívoros e de seus inimigos. Um manejo cuidadoso dessa vegetação pode contribuir para a diminuição de populações de pragas (ALTIERI; WHITCOMB, 1980). Pelo menos, dois mecanismos estão envolvidos nessa dinâmica. Em alguns casos, predadores e parasitóides, encontrando farta disponibilidade de recursos alimentares (hospedeiros ou presas alternativos, pólen e/ou néctar) e micro habitat em cultivos associados à vegetação espontânea, atingem níveis de abundância e diversidade capaz de impor maior taxa de mortalidade às pragas (VAN EMDEN, 1965; ROOT 1973; ALTIERI; LETOURNEAU, 1982).

É inquestionável que a vegetação espontânea estressa as culturas através dos processos de interferência e competição. Todavia, evidências substanciais indicam que a presença do "mato" em campos cultivados não pode ser pré-julgada como danosa e, por vezes, não requer controle imediato. Em geral, as interações entre as culturas e a vegetação espontânea são específicas para cada local e variam de acordo com as espécies envolvidas, fatores ambientais e agrícolas. Um dos maiores desafios do manejo da vegetação espontânea é assegurar a regulação das populações de insetos e evitar o período crítico de competição, isto é, o período máximo em que a vegetação espontânea pode ser sistema de cultivo sem afetar a produção (HOOKS; JOHNSON, 2003).

Para os cultivos de palma do nordeste paraense do município de Moju e do município de Tailândia, maior produtor 
paraense, Perez et al. (2007) recomendam o uso de adubos orgânicos quando estes forem acessíveis e viáveis ao produtor, pois a utilização deste tipo de adubo beneficia a microfauna e a microflora do solo, melhorando suas condições físicas, químicas e biológicas. Os resíduos provenientes da indústria de extração do óleo como o efluente, os cachos vazios e a torta (fibras do mesocarpo), poderão fazer parte da estratégia de adubação da cultura do dendê diminuindo os custos e a dependência dos adubos minerais.

O maior produtor de laranja do Pará, Capitão Poço, colocou-se na sétima posição pelo IDA. A produção de citros no Estado do Pará atingiu índices elevados de crescimento nos últimos dez anos, principalmente na microrregião do Guamá, onde se concentram os principais municípios produtores, além de Capitão Poço, somam-se Garrafão do Norte, Irituia e Ourém, os quais constituem o chamado pólo citrícola do Estado.

Os policultivos podem ser uma alternativa interessante para o manejo ecológico dos pomares paraenses, contudo, para um melhor entendimento da complexa dinâmica dos sistemas policulturais, determinada por processos que ocorrem no solo (competição entre plantas por água e nutrientes) ou na parte aérea (competição entre plantas por luz, água, nutrientes e interações planta-herbívoro, planta-inimigos naturais e planta-herbívoro-inimigos naturais), é importante estudar as respostas das pragas a esses múltiplos fatores. Portanto, incluem-se: densidade das espécies companheiras, cultivo simultâneo ou em épocas distintas, espaçamento entre fileiras das culturas, presença concomitante da vegetação espontânea, práticas específicas de manejo, além de condições edafo-climáticas, as quais por sua vez, influenciam as respostas dos cultivares selecionados, em termos de adaptabilidade e rendimento agronômico.

Quanto ao IDP, os 20 municípios com melhores desempenhos pecuários considerando a análise das variáveis integradas foram sintetizados na Tabela 2 . Responsável pelo maior rebanho bovino e caprino do estado e segundo maior criador de suínos, São Félix do Xingu encabeça a lista, sendo seguido por Muaná, município marajoara, maior criador de suínos, quinto colocado em rebanho bubalino, terceiro colocado em número de cabeças de caprinos. O terceiro colocado é o município de Chaves, maior criador de bubalinos e quinto maior de suínos.

Santarém ocupa a quarta posição, sendo o maior produtor de ovinos e segundo maior de caprinos, com rebanhos expressivos de bubalinos, suínos e aves. A Figura 1 apresenta a distribuição geográfica dos municípios em função do IDP. As mesorregiões Sudeste, Sudoeste e Baixo Amazonas apresentam grande aptidão às atividades pecuárias, juntamente com Marajó que apresenta grande aptidão histórica à criação de bubalinos. 
Tabela 2. Índice de Desempenho Pecuário dos 20 municípios melhores colocados entre os 143 municípios do estado do Pará.

\begin{tabular}{llllll}
\hline Posição & IDP & Município & Posição & IDP & Município \\
\hline $1^{\circ}$ & 0,737258 & São Félix do Xingu & $11^{\circ}$ & 0,30107 & Terra Santa \\
$2^{\circ}$ & 0,568632 & Muaná & $12^{\circ}$ & 0,29772 & São Geraldo do Araguaia \\
$3^{\circ}$ & 0,491835 & Chaves & $13^{\circ}$ & 0,29442 & Breu Branco \\
$4^{\circ}$ & 0,466295 & Santarém & $14^{\circ}$ & 0,29210 & Oriximiná \\
$5^{\circ}$ & 0,366318 & Rondon do Pará & $15^{\circ}$ & 0,28982 & São João de Pirabas \\
$6^{\circ}$ & 0,358629 & Altamira & $16^{\circ}$ & 0,28580 & Rurópolis \\
$7^{\circ}$ & 0,339356 & Marabá & $17^{\circ}$ & 0,28301 & Prainha \\
$8^{\circ}$ & 0,311486 & Itaituba & $18^{\circ}$ & 0,28023 & Monte Alegre \\
$9^{\circ}$ & 0,303150 & Novo Repartimento & $19^{\circ}$ & 0,27989 & Santa Maria das Barreiras \\
$10^{\circ}$ & 0,301654 & Tucumã & $20^{\circ}$ & 0,27910 & Pacajá \\
\hline
\end{tabular}

A vocação pecuária de Santarém está atrelada a grande produção de soja do município, principal matéria-prima de rações para as criações. Neste sentido há inclusive acordos de pequenos criadores com a empresa Cargill, que fornece material de refugo dos armazéns do porto para a produção de ração a preço simbólico, fomentando as pequenas criações no município. A atividade pecuária no Pará é uma das principais atividades produtivas do estado, estando presente tanto nas pequenas propriedades quanto nas grandes e tem se expandido quase continuamente em toda a história recente da ocupação da Amazônia.

A expansão da pecuária no estado é resultado não somente da rentabilidade da atividade, mas pela interação complexa de múltiplos aspectos como liquidez da atividade, à relativa simplicidade dos processos produtivos, bem como do baixo nível de investimento de capital necessário à sua instalação e facilidade de manejo em relação a outras atividades. (HOMMA et al., 2003; RODRIGUES, 2005).

Um ponto importante da atividade pecuária extensiva, é que ela é favorecida no Pará pelo grande número de assentamentos de reforma agrária. Em função da pressão social, o INCRA intensificou o processo de regularização fundiária e a criação de assentamentos no Sudeste do estado. O assentamento em fazendas totalmente formadas por pastagens é um tipo de assentamento diferenciado que modifica as estratégias de uso do espaço, favorecendo o processo de pecuarização da região. No processo de evolução do uso da terra, em 
geral, as famílias partiram de áreas cobertas conversão em pasto. de mata para a exploração agrícola até a

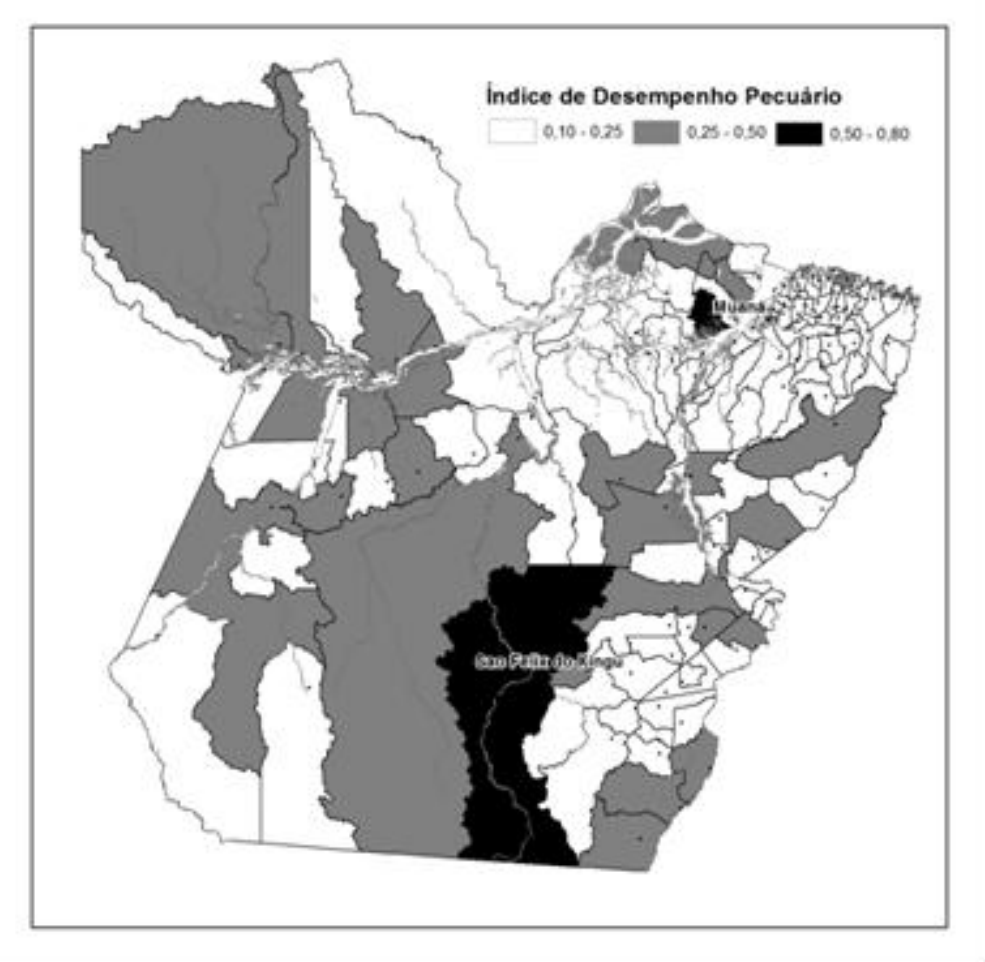

Figura 1. Classificação dos 143 municípios do estado do Pará em função do Índice de Desempenho Pecuário de cada município.

Os pequenos produtores assentados, após curta permanência com lavouras de arroz, milho, mandioca, abacaxi e banana, convertem rapidamente seus plantios em pastagens, contudo, no médio prazo esse processo pode resultar na falência dessas pequenas propriedades, devido à insustentabilidade da pecuária em pequenas áreas (ALVES; HOMMA, 2004).

Neste processo, conforme Homma (2003), um dos grandes problemas da pecuária no estado do Pará é a degradação dos solos, principalmente como resultado do superpastejo que os agricultores, em geral, conferem aos pastos. A baixa fertilidade dos solos provoca o abandono das terras convertidas para pasto (depois de 10 a 20 anos) e o pousio das terras com cultivos de ciclo curto (depois de três a quatro anos) (ALFAIA et al., 2004; DENICH et al., 2005). A paisagem resultante do processo de colonização é um mosaico de terras ocupadas e florestas secundárias de idades diversas (VIEIRA; SANTOS, 1987).

Para o problema de queda na fertilidade dos solos, Oliveira (2000) observou que a aplicação da matéria orgânica propiciou melhor desenvolvimento da planta, absorção de nutrientes e melhor produção de Brachiaria brizantha, que é a forragem mais 
utilizada nos pastos paraenses. A influência do calcário no desenvolvimento da planta é maior em solos mais ricos com matéria orgânica, seja em solo onde se aplica esterco ou em solo que originalmente contenha maiores teores de matéria orgânica. Desta forma, os solos paraenses explorados pela pecuária que já perderam a massa verde da floresta para a implantação da pastagem, necessitam da complementação de matéria orgânica no solo para compensar essas perdas.

Debates vêm sendo feitos no sentido de contribuir com a diminuição da importância relativa da pecuária bovina nos sistemas de produção paraenses, por meio de sua qualificação, ou seja, migrar de uma pecuária de corte extensiva para uma pecuária leiteira a pasto mais intensiva, com manejo mais adaptado e maior rentabilidade, podendo ser combinada com o cultivo de essências florestais (sistema silvipastoril) (INCRA 2006). A minimização dos impactos ambientais da pecuária por meio da arborização de pastagens, em particular com leguminosas arbóreas fixadoras de nitrogênio, é uma alternativa que visa principalmente aumentar a qualidade do solo.

Nos sistemas silvipastoris, os principais aportes orgânicos ao solo são resultantes da senescência do material foliar das árvores e da morte de raízes das gramíneas. A atividade da rizosfera e a posterior rizodeposição podem atuar na restauração de propriedades químicas e físicas do solo, como foi verificado em pastagens de Digitaria decumbens na
Martinica (BLANCHART et al., 2004). A macrofauna do solo, em sinergia com as plantas, é capaz de potencializar tais efeitos. Blanchart et al. (2004) também constataram experimentalmente que a atividade de minhocas proporcionou um aumento na estabilidade de agregados do solo, nessas mesmas pastagens.

Outro aspecto importante no manejo das criações no Pará, é a queima sazonal das pastagens para renovação e eliminação de ectoparasitas (PINHEIRO et al., 2007). Nesse aspecto, Oliveira e Franklin (1993), observando efeito do fogo sobre a mesofauna do solo, reconheceram que a perturbação exercida no ambiente resulta no desaparecimento de vários grupos taxonômicos, principalmente, nos períodos iniciais após a queima. Na mesma pesquisa concluiu-se que a baixa densidade de Colembola, observada na área queimada, sugeriu a sensibilidade deste grupo de insetos à ação do fogo, e sua recolonização está fortemente relacionada com o desenvolvimento da cobertura vegetal. Portanto, torna-se necessária a redução do uso do fogo no manejo das pastagens paraenses, de forma a reduzir impacto na fauna edáfica.

\section{CONCLUSÕES}

$\mathrm{Na}$ busca por sistemas agrícolas sustentáveis no estado do Pará, de baixo uso de insumos e energeticamente eficientes, uma estratégia é restaurar a diversidade da paisagem agropecuária dentro e no entorno do 
estabelecimento agrícola, nos quais a diversidade pode ser melhorada no tempo, o que pode ser alcançado por meio da rotação de culturas por exemplo, e, no espaço, podese otimizar a forma de cultivos de cobertura, adotar policulturas, sistemas agrossilvipastoris, cercas vivas, conservação de fragmentos de florestas, corredores ecológicos e matas ciliares, dentre outros.

Certamente, a diversificação dos agroecossistemas paraenses não resultará apenas na regulação das pragas com a restauração do controle natural, mas também otimizará a reciclagem de nutrientes, conservação do solo, conservação da energia, da água e implicará em menos dependência de insumos externos.

Contudo, é importante ressaltar que os efeitos das diferentes formas de diversificação dos cultivos não são universais. Cada situação deve ser avaliada separadamente. Ademais, as estratégias de manejo da vegetação em longo prazo também precisam ser desenvolvidas levando em consideração não apenas os fatores ecológicos, mas também os fatores sociais, econômicos e culturais para que a diversificação possa satisfazer as necessidades locais e preferências dos agricultores para atingir a sustentabilidade em seu sentido amplo: ambientalmente correta, economicamente viável, socialmente justa e culturalmente adaptada.

Por fim, relata-se que no estado do Pará, pouco tem sido registrado a respeito dos efeitos da diversidade vegetal nas populações de pragas e inimigos naturais, e menos ainda, sobre como manejá-la para melhorar a condição do solo por intermédio da fauna edáfica. Nesse contexto, é necessária a geração de mais conhecimento para as condições amazônicas, visando consolidar o manejo de pragas e do solo através da manipulação da biodiversidade nos agroecossistemas.

\section{REFERÊNCIAS}

ALFAIA, S. G. R.; RIBEIRO, A. D.; NOBRE, R. C.; LUIZÃO, E. F. J. Evaluation of soil fertility in smallholder agroforestry systems and pastures in western Amazonia. Agriculture Ecosystems \& Environment, v. 102, p. 409-414, 2004.

ALTAIN, A. Pagamento por serviços ambientais: aspectos jurídicos para sua aplicação no Brasil. 2010. Disponível em: <www.planetaverde.org/artigos/arq_12_51_4 3_26_10_10.pdf >. Acesso em: 31 mai. 2011.

ALTIERI, M. A. Biodiversity and pest management in agroecosystems. New York: Food Products Press, 1994.185 p.

ALTIERI, M. A.; SILVA, N. E.; NICHOLLS, C. I. O papel da biodiversidade no manejo de pragas. Ribeirão Preto: Editora Holos, 2003. 226 p.

ALTIERI, M. A.; WHITCOMB. W. H. Weed manipulation for insect management in corn. Environmental Management, New York, v. 4, n. 1, p. 483-489, 1980. 
ALTIERI, M. A.; LETOURNEAU, D. L. Vegetation management and biological control in agroecosystems. Crop Protection, v. 1, n. 1, p. 405-430, 1982.

ALVES, R. N. B; HOMMA, A. K. O. Pecuária versus diversificação da produção nos projetos de assentamentos no Sudeste Paraense. Belém: Embrapa Amazônia Oriental (Circular Técnica, 97), 2004. 6 p.

ANDOW, D. A. Vegetational diversity and arthropod population response. Annual Review of Entomology, Palo Alto, v. 36, n. 1, p. 561-586. 1991.

ARATO, H. D.; MARTINS, S. V.; FERRARI, S. H. S. Produção e decomposição de serapilheira em um sistema agroflorestal implantado para recuperação de área degradada em Viçosa-MG. R. Revista Árvore, Viçosa, v. 27, n. 5, p. 715-721, 2003.

ATKINS, M. D. Insects in perspective. New York: Macmillan Publishing, 1978. 513 p.

BACHELIER, G. La faune des sols, son écologie et son action. Orstom: Documentations Tecnhiques, n. 38, 1978. 391 p.

BETTIOL, W.; GHINI, R.; GALVÃO, J. A. H.; LIGO, M. A. V.; MINEIRO, J. L. C. Soil organisms in organic and conventional cropping systems. Scientia Agricola, Piracicaba, v. 59, n. 3, p. 565-572, 2002.
BLANCHART, E.; ALBRECHT, A.; CHEVALLIER, T.; HARTMANN, C. The respective roles of roots and earthworms in restoring physical properties of Vertisol under a Digitaria decumbens pasture (Martinique, WI). Agriculture, Ecosystems \& Environment, Amsterdam, v. 103, n. 1, p. 343-355, 2004.

BOYD, J.; BANZHAF, S. What are ecosystem services? The need for standardized environmental accounting units. Ecological Economics, v. 1, n. 2-3, p. 616626, 2007.

BRANDÃO, J. R. A cultura do cacau em SAF: reflexões sobre identificação e valoração de serviços ambientais e socioeconômicos na Transamazônica. Belém, 2008, 77 f. Monografia (Especialização em Planejamento e Gestão de Recursos Hídricos e Ambientais) Universidade Federal do Pará, Belém, 2008.

CALVI, M. F. Fatores de adoção de sistemas agroflorestais por agricultores familiares do Município de Medicilândia, Pará. Belém, 2009, 79 f. Dissertação (Mestrado em Agriculturas Amazônicas) Universidade Federal do Pará, Belém, 2009.

CHEE, Y. E. An ecological perspective on the valuation of ecosystem services. Biological Conservation, v. 1, n. 120, p. 549-565, 2004.

DAILY, G. C. Introduction: what are ecosystem services. In: DAILY, G.C. (Ed.) 
Nature's Services: Societal Dependence on Natural Ecosystems. Washington: Island Press,1997. p. 1-10.

DAVIES, A. M. C., FEARN, T. Back to basics: the principles of principal component analysis. Spectroscopy Europe, v. 16, n. 6, p. 20-23, 2004.

DEMITE, P. R.; FERES, R. J. F. Influência de Vegetação Vizinha na Distribuição de Ácaros em Seringal (Hevea brasiliensis Muell. Arg., Euphorbiaceae) em São José do Rio Preto, SP. Neotropical Entomology, v.34, p. 829-836, 2005.

DENICH, M.; VLEK, P. L. G; SÁ, T. D. D. A; VIELHAUER, K.; LÜCKE, E. W. A concept for the development of fire-free fallow management in the Eastern Amazon, Brazil. Agriculture Ecosystem and Environment, v. 1, n. 110, p. 43-58. 2005.

FERREIRA, J. H. O.; KATO, M. S. A. Influência do método de preparo da área na mesofauna do solo na região Nordeste do Pará. In: SEMINÁRIO DE INICIAÇÃO CIENTÍFICA DA EMBRAPA AMAZÔNICA ORIENTAL, 1., 2003. Resumos... Belém: Universidade Federal Rural da Amazônia, 2003.

FISHER, B.; TURNER, R. K.; MORLING, P. Definig and classifying ecosystem services for decision making. Ecological Economics, v. 1, n. 68, p. 643-653, 2009.
FRANCIS, C. A.; FLOR, C. A.; TEMPLE, S. R. Adapting varieties forintercroppped systems in the tropics. In: TRIPLETT, G. B.; SANCHEZ, P. A.; PAPENDICK, R. I. (Ed.). Multiple cropping. Madison: American Society of Agronomy, 1976. v.1, p. 1-10. (ASA Special Publication, 27).

GLIESSMAN, S. R. Agroecologia: processos ecológicos em agricultura sustentável. Porto Alegre: Editora Universidade Federal do Rio Grande do Sul, 2. Ed. 653pp. 2002.

HAIR, J. F.; ANDERSON, R. E.; TATHAM, R. L.; BLACK, W. C. Multivariate Data Analysis: With Readings. New Jersey: Prentice Hall, 1995.

HAJEK, A. E. Conservations and Enhancement of Natural Enemies. In: Departament of entomology cornell University. Natural Enemies: an introduction to biological control. New York: Cambridge University Press, 2004. v. 1, p. 80-96.

HAAWKEN, P.; LOVINS, A. B.; LOVINS, L. H. Natural Capitalism. London: Earthscan Publications Ltd, 1999.

HOMMA, A. K. O. Cronologia da ocupação e destruição dos castanhais no Sudeste Paraense. Belém: Embrapa Amazônia Oriental, 2000. 132p.

HOOKS, C. R. R.; JOHNSON, M. W. Impact of agricultural diversification on the insect 
community of cruciferous crops. Crop Protection, v. 22, n. 1, p. 223-238, 2003.

IBGE. Instituto Brasileiro de Geografia e Estatística. Base de dados do Censo Agropecuário, n. 3, Rio de Janeiro: IBGE, 2006.

INCRA. Instituto Nacional de Colonização e Reforma Agrária. Dados sobre assentados no Brasil, por município. Brasília: Superintendência de Desenvolvimento Agrário, 2006.

KARLEN, D. L.; MAUSBACH, M. J.; DORAN, J. W.; CLINE, R. G.; HARRIS, R. F.; SCHUMAN, G. E. Soil quality: a concept, definition, and framework for evaluation. Soil Science, v. 61, p. 4-10, 1997.

LANDIS, D. A., WRATTEN, D. S.; GURR, G. M. Habitat management to conserve natural enemies of arthropod pests in agriculture. Annual Review of Entomology, v. 45, p. 175-201, 2000.

LEITÃO-LIMA, P. S.; TEIXEIRA. L. B. Distribuição vertical e abundância da mesofauna do solo em capoeiras. Belém: Embrapa Amazônia Oriental, 2002. (Comunicado técnico, n. 63).

MACDIKEN, K. G.; VERGARA, N. T. Introduction to agroforestry. In: MACDIKEN, K. G.; VERGARA, N. T. (Eds.). Agroforestry: classification and management. New York: John Wiley \& Sons, 1990. v.1, p. 1-30.

MENDONÇA, E. S.; LEITE, L. F. C.; FERREIRA-NETO, P. S. Cultivo de café em sistema agroflorestal: uma opção para recuperação de solos degradados. Revista Árvore, v. 25, n. 3, p. 375-383, 2001.

MORAES, G. J., ALENCAR, J. A., LIMA, J. L. S., YANINEK, J. S.; DELALIBERAJUNIOR, I. Alternative plant habitats for common phytoseiid predators of the cassava green mite (Acari: Phytoseiidae, Tetranychicae) in northeast of Brazil. Experimental \& Applied Acarology, v. 17, p. 77-90, 1993.

NICHOLLS, C.I.; ALTIERI, M.A.; SANDEZ, E.J. Manual practico de control biologico para una agricultrura sustentable. Berkeley: University of California, 1999. 69 p.

OLIVEIRA, E. P.; FRANKLIN, E. Efeito do fogo sobre a mesofauna do solo: recomendações em áreas queimadas. Pesquisa Agropecuária Brasileira, v. 28, n. 3, p. 357-369, 1993.

OLIVEIRA, I. P.; CUNHA, R.; SANTOS, R. S. M. Efeito da correção da fertilidade do solo no desenvolvimento da Brachiaria brizantha cv. Marandu em Latossolo com diferentes históricos. Revista Pesquisa Agropecuária Tropical, v. 30, n. 4, p. 57-64, 2000. 
PEREZ， R.; SILVA-JÚNIOR， A. G.; MIRANDA, C. A.; SANTOS, M. M. S. Viabilidade de extração de óleo de dendê no estado do Pará: Projeto biodiesel. Viçosa: Universidade federal de Viçosa/Ministério do Desenvolvimento Agrário, 2007.112 p.

PINHEIRO, A. R. Caracterização da fauna edáfica em sistema de roça de corte e queima em São João do Araguaia-PA. Marabá, 2008, 87 f. Monografia de Conclusão de Curso (Bacharelado em Agronomia)Universidade Federal do Pará, Marabá, 2008.

REBELLO, F. K.; RAELE FILHO, H. B.; FIGUEIREDO, R. N. C. Diagnóstico e perspectiva econômica da cadeia produtiva do coco-da-baía no estado do Pará. Belém, 2001, 67 f. Monografia de Conclusão de Curso (Especialização em Agricultura Integrada na Amazônia)-Faculdade de Ciências Agrárias do Pará, Belém, 2001.

RODRIGUES, M. S. O sistema de criação de bovinos no Assentamento Agroextrativista Praialta Piranheira: Importância e Diversidade. Marabá, 2005, 108 f. Monografia de Conclusão de Curso (Licenciatura plena em Ciências Agrárias)Universidade Federal do Pará, Marabá, 2005.

ROOT, R. B. Organization of plant arthropod association in simpleand diverse habitats: the fauna of collards (Brassica oleraceae). Ecology Monographs, v. 43, p. 95-124, 1973.
SANTANA, A. C. Crescimento e estrutura da produção agrícola na Amazônia. Belém: Faculdade de Ciências Agrárias do Pará, 1988, p. 57-78. (Boletim, n. 17).

SCHOOHONVEN, L. M.; JERMY, T.; VAN LOON, J. J. A. Plant chemistry: endless variety. In: SCHOOHONVEN, L. M.; JERMY, T.; VAN LOON, J. J. A. (Ed.). Insect-plant biology: from physiology to evolution. New York: Chapman \& Hall, 1998. p. 23-47.

VAN EMDEN, H. F. The role of uncultivated land in the biology of crop pests and beneficial insects. Scientific Horticulture, v. 17, p. 121-136, 1965.

VANDERMEER, J. The ecology of intercropping. Cambridge: Cambridge University Press, 1989. 237 p.

VIEIRA, L. S.; SANTOS, P. C. T. C. Amazônia: seus solos e outros recursos naturais. Viçosa: Editora Ceres, 1987. 8 p. 